\title{
EDITORIAL/EDITORIAL
}

\section{...the timeline...}

\begin{abstract}
It was 1967.
The former Department of Statistics, at the School of Hygiene and Public Health at Universidade de São Paulo (USP), had concluded a study about fertility in São Paulo and getting ready to begin a new research. It was an international investigation about childhood mortality, led by Doctor Ruth Puffer, from the Pan American Health Organization/World Health Organization (PAHO/WHO), in Washington, scheduled to be conducted in many cities of the America. Ruy Laurenti, a young doctor, graduated in 1957 at USP, had just arrived from his course about Vital Statistics and Classification of Diseases, in Chile, was chosen to be in charge of the project.

I had been nominated by the Professors Elza Berquó and Maria Lucila Milanesi to coordinate the field work of this investigation.

In this context, I met Ruy Laurenti and worked with him for 47 years.
\end{abstract}

The study in question brought an important recognition to the Professor, from constant compliments - because of its excellent conduction - to the use of its results in initiatives carried out by the Secretariat of Health, in the first administration of Professor Walter Leser to assist the reduction in childhood mortality among children in São Paulo.

That was Ruy. He was remarkable wherever he went.

His $\mathrm{PhD}$ thesis, in 1969, which received the Gold Medal Ovídio Pires de Campos, was considered to be the best thesis in the Department of Medical Clinic at the Medical School of USP.

In 1971, in the School of Public Health, his story remained brilliant, and in 1973, when he became an Associate Professor, was the year he definitely joined the Public Health field.

Important facts have marked the 1970s.

1975, Minister of Health, Paulo de Almeida Machado: Ruy Laurenti is invited to take part in a small group of experts who should study the creation of a System of Health Information in the country. It was the starting point for the studies about mortality. Models and flow of the standardized Death Declaration - which are now considered to be simple - did not exist at that time. Then, came the Professor, as he always said, "with his suitcase in his hand, travelling from North to South of this country," to convince medical associations, health secretariats, and universities that data on mortality rates were essential to the Health administration, that an information system in this field was a priority, and that the death certificate made by the doctor had to be completely filled out. 
Despite the obstacles, the System on Mortality Information (SIM) has grown, become important, and developed, with the constant collaboration of Professor Ruy, in his studies of evaluation and struggle for improvements in the coverage and quality of the data.

Another relevant fact was the creation, in 1976, of the Brazilian Center of Disease Classification, which resulted from a partnership between PAHO/WHO, the Ministry of Health, and USP, where he has been a director ever since. The Center was in charge of studying problems regarding the structure, the interpretation, and the application of the International Classification of Diseases, assisting the Ministry of Health and PAHO/WHO in direct and correlated activities, and promoting courses for the specialized personnel in the field. Because of these tasks, in several opportunities, he was honored and acknowledged by these institutions.

The test to become a Titular Professor took place in 1979 and led Ruy Laurenti to high positions in the School of Public Health and in USP: Head of the Epidemiology Department, Vice-Director, Director, Member of the Congregation of the Nursing School, with no board at the time, Dean of Culture and Extension, 1st General Ombudsman, and Vice-Dean. At a tough time for the University, because of the resignation of the former Dean, he put aside some personal projects and administered USP with a lot of balance.

Classes, lectures, and counseling for students were always his tasks. Even if he assumed important jobs and positions, he returned to the University to "take care of his children." He counseled more than 40 people, many of whom are now professors inside and outside USP. He did it with joy, always manifesting trust and respect toward his students.

In 1989, after the success of SIM, he was "summoned" to integrate the Group of Vital Statistics, from the Ministry of Health, which, in that year, created and provided the System of Information about Born Alive (SINASC), now with unique coverage and quality.

In 1996, when researchers from the field of information in Health, at PAHO, got together and created the Inter-Agency Network of Information for Health (RIPSA), there was Professor Ruy as an "associate-founder," as a Master, and an inspiration for all of us.

Another important aspect of his academic life is that he was part of the Council at the São Paulo Research Foundation (FAPESP), where he worked for seven years. Similarly, he was the CEO of Fundação Oncocentro de São Paulo, from 1995 to 1999. In several activities, he collaborated with scientific magazines and was one of the major encouragers for the creation of Revista Brasileira de Epidemiologia, where he was part of the Editorial Board from the beginning.

August 2001: Not even the legislation, which determined his mandatory retirement for the 15th, was able to take Professor Ruy Laurenti away from the university life. The Senior Professor Program at USP, of which he was a part for 13 years, allowed him to continue with his studies, his classes, and made it so that new publications could be added to the already extensive scientific production in the fields of Epidemiology, Health Statistics, Classification of Diseases, Information in Health, and Maternal Health. 
Two important studies financed by FAPESP, the National Council of Scientific and Technological Development (CNPq), and PAHO date from this period: maternal mortality and the analysis of the mother-child binomial; for the latter, studies are still being concluded.

USP recognized the qualities of Ruy Laurenti at fulfilling the three pillars of the University teaching, research, and services to the community — and granted him the honorable title of Professor Emeritus in 2003.

In 2007, he became a titular member of the Academy of Medicine of São Paulo, and in 2013, for the relevant services provided to Medicine, he received the commendation Sergio Arouca, from the Federal Council of Medicine.

In 2014, an agreement was signed with the Regional Council of Medicine of São Paulo for the revision of the "green book" about death certificates - which the Council began to manage - and for the elaboration of a publication about "Information in Health: the role of the doctor." It was another dream coming true.

For the studies that marked all of his history in USP and as a recognition of the relevant scientific and academic contributions, he was honored by CNPq with the title of Professor Emeritus. He could not attend the ceremony, but Professor Victor Wünsch Filho, our Director, very sensitive and proud, represented him on behalf of the School of Public Health at the award celebration, on May 5.

June 12, 2015: Fate takes Professor Ruy Laurenti from our lives.

He left us; however, as a legacy, he left the example that, at work, it is important to keep fighting for the things one believes in — without ever stopping — , accepting new tasks and the challenges of life.

In our heads and hearts, we will keep the memory that Ruy Laurenti, in spite of being nationally and internationally recognized in the Health field, always kept his simplicity, which was, after all, his trademark.

Now, I speak for myself.

Ruy, your School says goodbye. Your life and work, however, will continue to be reference for your team, your friends, and your students. We would like to thank you for everything you taught us and all you did for Public Health in this country

São Paulo, July 4, 2015

Maria Helena Prado de Mello Jorge 